\section{Response to Huggins and Hayden}

SIR

In response to the letter by Ms Huggins and Dr Hayden, I can only thank them for supplying information on the current genetic technology in the diagnosis of Huntington Disease. Such information was not available to me at the time of writing the essay, and therefore I wrote on the presumption that the condition could be diagnosed to some extent by DNA analysis. As such technology is advancing rapidly, but being aware that test results may still be inconclusive in providing a diagnosis, I did make provision in my essay for circumstances in which test results were dubious.

Ms Huggins and Dr Hayden state that the doctor must not act directly against the wishes of his patient. When, after the mother's condition has deteriorated to the extent that the daughter is having to care for her, the daughter questions the general practitioner (GP) about the mother's illness, should the GP still refuse to inform the daughter of her mother's condition? Can there be such an absolute obligation to the mother? Although the mother may be too ill to realise it by this point, it may be in the mother's best interests for the daughter, as caregiver, to know fully about the disease. One must assess how profoundly this information will affect the lives of the children, and only with this consideration in mind can the obligation to the mother be judged.

JEAN ADAMS, BNurs, MA, RN, SCM, clo Curtis Memorial Hospital, St Anthony, Newfoundland, Canada, AOK $4 S O$.

\section{Enforced death: enforced life}

\section{SIR}

Gavin Fairbairn (Enforced death: enforced life, Fournal of medical ethics $1991 ; 17: 144)$ quotes a suggestion that a new medical specialty of doctors who combine hospice care with euthanasia should be established. Perhaps he is unaware that the Association for Palliative Medicine in this country and the European Association for Palliative Care both consider that the direct and intentional killing of patients is unacceptable. As hospice doctors, we applaud the fact that palliative care is being discussed positively by the European Parliament but consider it most unfortunate that the report being presented includes a short section favouring euthanasia.

My personal objection to such a step is not merely based upon a personal ethical stance but upon an awareness of the social pressures that would be brought to bear on many vulnerable people should a 'right to die' be legalised. Good palliative care needs to be spread far more widely and this is the concern of many of us in this field. Where it is unavailable, or even unavailing, the few who might still find an 'enforced life' intolerable must call on our understanding and compassion. They cannot achieve a legal right without undermining the confidence in deserved care that should support the great majority.

DAME CICELY SAUNDERS, OM, DBE, FRCP, Chairman, St Christopher's Hospice, 51-59 Lawrie Park Road, Sydenham, SE26 6DZ.

\section{Enforced death: enforced life - another response}

SIR

Gavin Fairbairn's article is an interesting article born out of much thought. However, I wish to make the following points which weaken his argument substantially (1). My comments necessarily concentrate on 'the end of life' within the context of terminal care since that is my current area of work and the source of my observations.

It is disingenuous to say that doctors 'guard their own quality of life at the patient's expense' because they believe that the act of euthanasia is not acceptable. While I accept that in some instances individuals may constantly and consistently request 'euthanasia' on account of poor quality of life it is legitimate that this is treated with the utmost caution and fully explored. The predominant issue however must be a commitment to continue caring, even though the patient may be 'hopelessly ill' (2). After all, one of the central tenets of medical ethics, Primum non nocere, translates as 'first do no harm'.

The recent case of Dr Timothy Quill reveals a fascinating insight into the vexed question of euthanasia (3). In the many letters which followed, many did concentrate on the fact that he contin- ued to provide highly personalised care even though the patient was 'hopelessly' and irrevocably ill (4). The bottom line of all this must be that the question of implementing an act of euthanasia must be treated with great circumspection and caution. In a recent conference in The Netherlands (First Conference on the Biopsychosocial Aspects of HIV Infection, 22-25th September 1991, Amsterdam) one of the most pertinent points made, was the reluctance of elderly patients to enter hospitals where euthanasia was practised. It is a fine line which separates a patient-determined, and rational desire for euthanasia and enforced euthanasia.

My final point refers to Fairbairn's support for possible objections to his position (2nd paragraph), where it is argued that inadequate terminal care facilities would support a request for euthanasia. He does go on to say such a scenario should encourage 'hospicetype provision' to be more widely available. My point here is that requests like this are all too common and this is one of the reasons why the hospice movement has been so successful in the past twenty years in the UK. One of many continuing deficiencies highlighted in a recent report (5) is the lack of training and skills in this area of clinical medicine. How could this be tackled if there is early recourse to euthanasia, since the stimulus to change will have disappeared in a good many cases? One point aside here is that there are many ways of meeting palliative care needs, transfer to a hospice being one among many and diverse options available.

\section{References}

(1) Fairbairn G. Enforced life: enforced death. Fournal of medical ethics 1991; 17: 144-149.

(2) Wanzer S H, Federman D D, Adelstein S J et al. The physician's responsibility toward hopelessly ill patients, a second look. New England journal of medicine 1989; 320: 844-849.

(3) Quill T E. Death and dignity - a case of individualised decision making. New England journal of medicine 1991; 324: 691-694.

(4) Death and dignity: the case of Diane [letter]. New England journal of medicine 1991; 325: 658-660.

(5) Dying with dignity. London: Office of Health Economics, 1991.

SURINDER SINGH, MRCGP, Medical Officer, London Lighthouse and General Practitioner, 53 Shell Road, Lewisham, London SE13 7DF. 